\title{
The differential diagnosis of caring
}

$\mathrm{O}$ ur patient lived alone, in an unkempt apartment where she hoarded and hid. She had been admitted to hospital three or four times in the past few years for psychiatric reasons. Each time on admission she had refused a physical exam. We're not sure whether she was offered one once she was less delusional, less agitated and less fearful in other words, when she had been treated for her presenting illness, schizophrenia.

For several months she had been talking about her concern that her breast was poisoned - a belief that was thought to be delusional, a part of her schizophrenia.

Then two weeks ago, on meeting her for the first time, a nurse on our Outreach Team decided to look at this "poisoned breast." She did what we always need to do when we work with Outreach clients, she improvised, and took her into a Ladies washroom. The nurse was horrified by what she saw a red, warm, swollen breast "with funny skin." Textbook inflammatory breast cancer. The poor woman was cradling her arm, as it was painful to

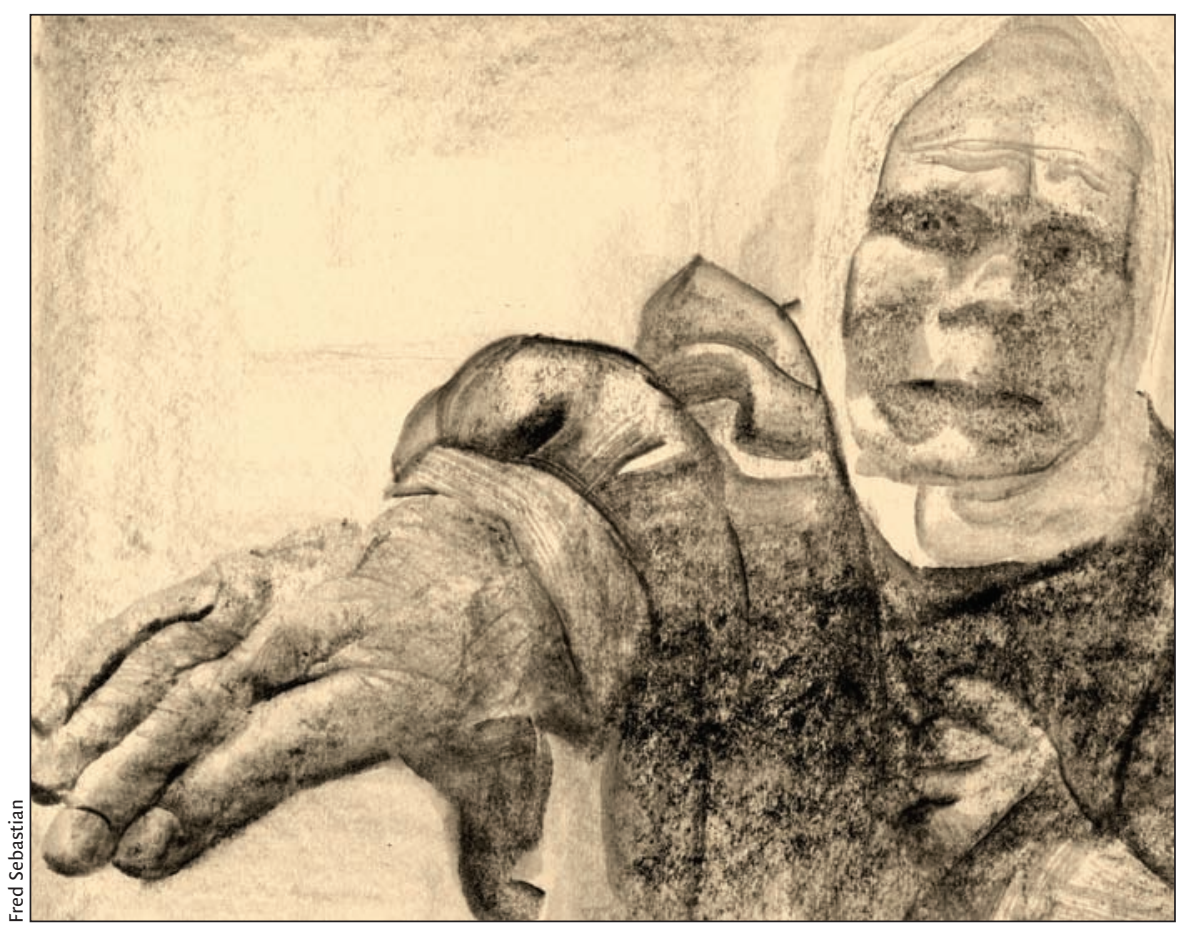

appointments to keep, with no family support and no trust in the medical profession due to years of severe schizophrenia ... an illness where some of the cardinal symptoms are paranoid delusional beliefs, disorganized

\section{She had been talking about her con- cern that her breast was poisoned}

move. The nurse immediately drove her to one of the local Emergency Departments, where she was seen by Surgery. Not admitted. Sent home with an Outpatient appointment. Sent home with lists of treatment options, side effects, thought-process (making decisionmaking very difficult), poor planning ability, lack of social supports, social isolation, low income, and poor ability to report concerns and side effects.

Our Team rejoiced when our patient was admitted to the Hospice for the Homeless. In the same way we "rejoiced" when she received the diagnosis of breast cancer. We rejoiced that she was listened to and would now be with nurses who understand the destitute who are medically ill, those who don't know when to bathe or how to cook or keep themselves clean. She would have transportation to appointments, reminders for appointments, reminders to take medications, reminders to smile.

She died soon after admission, surrounded by care; her family thanked our Outreach nurse for her part in caring for our patient.

Donna Lougheed

Psychiatrist 